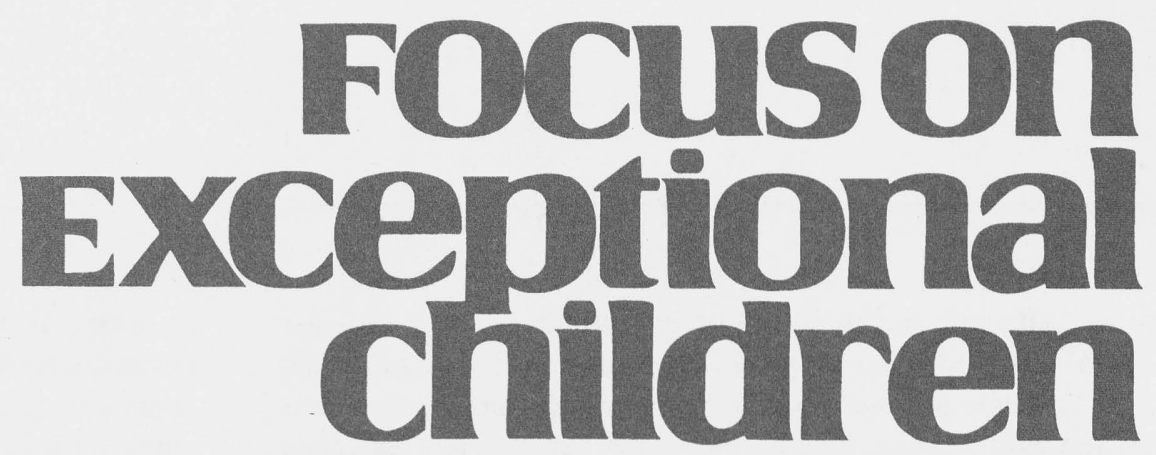

\title{
Why They Say No: Foundational Precises and Techniques for Managing Resistance
}

\author{
John W. Maag
}

Why do they say no? Practitioners often have agonized with, and mulled over, this question when faced with a familiar, yet vexing problem of many youth: managing their resistance. Youth who display challenging behaviors are often perceived to be noncompliant, disobedient to directions, uncooperative, and oppositional. Serious noncompliant behavior is one of the most frequent reasons young children are referred for psychiatric services (Kuczynski, Kochanska, Radke-Yarrow, \& Girnius-Brown, 1987). Noncompliance serves as a "gateway behavior" for children developing serious antisocial behavior (Walker, Colvin, and Ramsey, 1995). It can lead to tantrums, uncooperativeness, aggression, then stealing, and ultimately delinquency. In some instances, engendering compliance can prevent children from developing more serious antisocial behavior (Walker et al., 1995). Compliance typically has been conceptualized as obedience to adult directives and prohibitions, cooperation with requests and suggestions, and willingness to accept suggestions in teaching situations (Rocissano, Slade, \& Lynch, 1987).

Severe oppositional behaviors have become so pervasive that they were classified as a psychiatric disorder about 20 years ago in the third edition of the Diagnostic and Statistical Manual of Mental Disorders (DSM-III; American Psychiatric Association, 1980). The DSM-III criteria required the presence of at least two of the following symptoms over a 6-month period: violations of minor rules, temper tantrums, argumentativeness, provocative behavior, and stubbornness. The term oppositional-defiant disorder first appeared in the revised version of the third edition (DSM-III-R; APA, 1987). The current diagnostic criteria appearing in the fourth edition (DSM-IV; APA, 1994) requires a pattern of negativistic, hostile, and defiant behavior lasting 6-months in which at least four of the following eight symptoms are present: temper outbursts, arguing with adults, refusing to follow adult requests, deliberately annoying people, blaming others for own mistakes, touchy or easily annoyed by others, angry and resentful, and spiteful or vindictive.

\footnotetext{
John Maag is with the Department of Special Education and Communication Disorders, University of Nebraska at Lincoln.
} 
Although the inclusion of oppositional-defiant disorder in the DSM nosology is questionable (Kazdin, 1989; McMahon \& Forehand, 1988), noncompliance nevertheless represents a practical problem for parents, teachers, and clinicians. Noncompliance typically involves disobedience to directives, uncooperativeness with requests and suggestions, and unwillingness to accept suggestions (Zirpoli \& Melloy, 1997). In some instances, noncompliance is displayed by providing no response at all (Schoen, 1986). In the latter instance, these children often are called passiveaggressive - a term associated with Freud's psychodynamic theory that is clearly oxymoronic. How can a child be simultaneously both aggressive and passive?

Nevertheless, oppositional-defiant disorder is believed to occur in between $2 \%$ and $16 \%$ of children, depending on the nature of the population sample and methods of estimation (American Psychiatric Association, 1994). These estimates should not come as a surprise, as children traditionally have disobeyed about $20 \%$ to $40 \%$ of parental requests and commands (Forehand, 1977).

The behaviors of children who display longstanding resistance, noncompliance, or opposition are often unyielding to intervention. The most common treatment approaches

\section{FOCuson Exceptional children}

ISSN 0015-511X

FOCUS ON EXCEPTIONAL CHILDREN (USPS 203-360) is published monthly except June, July, and August as a service to teachers, special educators, curriculum specialists, administrators, and those concerned with the special education of exceptional children. This publication is annotated and indexed by the ERIC Clearinghouse on Handicapped and Gifted children for publication in the monthly Current Index to Journals in Education (CIJE) and the quarterly index, Exceptional Children Education Resources (ECER). The full text of Focus on Exceptional Children is also available in the electronic versions of the Education Index. It is also available in microfilm from Xerox University Microfilms, Ann Arbor, MI. Subscription rates: Individual, \$30 per year; institutions, \$40 per year. Copyright (C) 1999, Love Publishing Company. All rights reserved. Reproduction in whole or part without written permission is prohibited. Printed in the United States of America. Periodicals postage is paid at Denver, Colorado. POSTMASTER: Send address changes to:

Love Publishing Company Executive and Editorial Office P.O. Box 22353

Denver, Colorado 80222

Telephone (303) 221-7333
Edward L. Meyen University of Kansas

\section{Glenn A. Vergason} Georgia State University

Richard J. Whelan University of Kansas Medical Center involve a combination of highly contingent positive and negative consequences, providing clear, direct, and specific commands, and having children self-monitor and self-evaluate their behavior (Rhode, Morgan, \& Young, 1983; Walker et al., 1995; Zirpoli \& Melloy, 1997). Although most approaches for managing resistance have focused on childcentered interventions, Walker et al. (1995) insightfully noted that "whether or not a child complies with an adult directive has as much to do with how the command is framed and delivered as it does with the consequences, or lack of them, that follow the delivery" (p. 399).

They went on to describe the difference between alpha and beta commands. Alpha commands are given in a clear, direct, and specific manner with few verbalizations and allow a reasonable time for compliance. Beta commands are vague, overly wordy, and often contain multiple instructions to engage in a behavior. The implication of their discussion is that adults' behaviors may either exacerbate or ameliorate children's noncompliance.

The type of communication patterns that adults display when confronted with noncompliance illustrates that resistance may arise from a variety of sources - both individuals and behaviors. In fact, Cormier and Cormier (1985) stated that resistance can arise from any behavior, regardless of the source, that interferes with the likelihood of a successful outcome. This definition provides the impetus for using the term resistance instead of the more common words "noncompliance" and "oppositional" throughout much of this article.

\section{STATEMENT OF OWNERSHIP, MANAGEMENT AND CIRCULATION}

Date of Filing: September, 17, 1999

Title of Publication: Focus on Exceptional Children

Frequency of Issue: Monthly (except June, July \& August)

Location of Known Office of Publication: 9101 E. Kenyon Ave., Suite 2200, Denver, CO 80237

Location of Headquarters of Publisher: 9101 E. Kenyon Ave., Suite 2200, Denver, CO 80237

Name and Address of Publisher, Editor, and Managing Editor: Stanley F. Love, 9101 E. Kenyon Ave., Suite 2200, Denver, CO 80237

Owner: Love Publishing Company

Extent and Nature of Circulation:

Total No. Copies Printed

Paid Circulation

Sales through Dealers, etc.

Mail Subscriptions

Other Classes Mailed Through USPS

Total Paid Circulation

Free Distribution Outside the Mail

Free Distribution

Total Distribution

Office Use and Left Over

Total

$\begin{array}{cc}\begin{array}{c}\text { Average No. Copies } \\ \text { Each Issue During } \\ \text { Preceding 12 Months }\end{array} & \begin{array}{c}\text { Single Issue } \\ \text { Nearest } \\ 2292\end{array} \\ \begin{array}{c}\text { Filing Date } \\ 2400\end{array} \\ 0 & 0 \\ 2039 & 2110 \\ 0 & 0 \\ 2039 & 2110 \\ 0 & 0 \\ 152 & 176 \\ 2191 & 2286 \\ 101 & 114 \\ 2292 & 2400\end{array}$

I certify that the statements made by me above are correct and complete. 
Resistance is a more inclusive term because it focuses on the interaction between children's and adults' behaviors. On the other hand, the terms "noncompliance" and "oppositional," suggest that the locus of the problem resides within a youngster. Consequently, solutions to the problems of noncompliance or opposition will focus solely on changing youngsters' behaviors to the exclusion of modifying adults' behaviors. Successfully managing resistance requires attending to the behaviors of youngsters and adults alike.

The purpose of this article is to first present three foundational precises for managing resistance. A pair of essential ingredients are understanding the impact of context on behavior and the relation between noncompliant behaviors and the functions they serve. The nexus of context and function forms the basis of the third truism: If what you are doing is not working, try something else. The simplicity of this statement belies the difficulty that practitioners have in becoming unfettered by convention and adopting new patterns of behavior as a method of reducing resistanceregardless of the perceived source.

The second portion of this article is devoted to describing techniques for managing resistance that merge context, function, and adaptation. Throughout these discussions, we have to realize that managing resistance is not always a massive endeavor. Rather, small changes in individuals' behaviors - those of children and of adults - can set in motion larger changes in the direction of a desired outcome. In this respect, behavior change is like a kaleidoscope: Once the tube is turned even a fraction of an inch, the entire pattern changes (Rosen, 1982).

\section{FOUNDATIONAL PRECISES FOR MANAGING RESISTANCE}

A precis is a concise summary of the essential facts or statements regarding a topic of inquiry. The application, appropriateness, and effectiveness of interventions for managing resistance depend on a clear understanding of its underlying presuppositional foundations. An understanding of the impact and implications that context exerts on behavior, the relations between challenging behaviors and the functions they serve, the ability of adults to adapt their behavior, and the nexus between these three foundations are essential for effectively applying interventions for managing resistance.

\section{Impact and Implications of Context}

Behavior does not occur in a random or unorganized fashion. People behave purposely, and their behavior attains meaning as a function of the context-situation or circumstances - that exists in a particular environment (Maag, 1992). Environment is the universe of events and objects, both animate and inanimate, that are part of our surroundings (Johnston \& Pennypacker, 1993).

Some of these events are concrete and tangible. For example, a classroom environment is composed of animate objects, such as children and adults, and a host of inanimate objects including (but not limited to) tables, chairs, chalkboards, materials, and tasks.

Some events can be less visible and abstruse. For example, social norms (standard rules that state how individuals should behave under given circumstances) and cultural mores (social manifestations of norms) have a profound affect on the expression of behaviors and how they are interpreted (Clinard and Meier, 1995). This point is strikingly illustrated by the two following examples.

A widely held belief is that alcohol abuse is a major cause of family violence. In cases of spousal violence, offender and victim both have frequently been drinking before the violence. An oft-cited explanation for this association is that alcohol disinhibits violent tendencies. Gelles and Cornell (1985), however, pointed to cross-cultural studies of drinking behavior as evidence against the "disinhibitor" theory.

These studies found that how people react to drinking varies from culture to culture. In some cultures people drink and become violent, whereas in other cultures people drink and are passive. They went on to explain the difference in terms of what people in certain societies believe about alcohol. If they believe it is a disinhibitor, people become disinhibited. If they believe that it is a depressant, people become depressed. Gelles and Cornell ended their discussion by stating that, because our society believes that alcohol releases violent tendencies, people are given a "time out" from normal rules of social behavior when they drink or when people believe they are drunk.

A second, and equally telling, example can be found by examining the sociocultural context of anorexia nervosa. The relentless pursuit of thinness that is typical of many anorexics is little more than a caricature of what American society considers beautiful. Schwartz, Thompson, and Johnson (1982) believed that the increase in anorexia nervosa reflects our cultural preoccupation with thinness in women and revulsion of obesity and excessive eating.

Most revealing was their comparison of anorexia nervosa and hysteria - both predominantly manifested in womenacross cultures. Hysteria, now considered one of the somatoform disorders, is a condition in which emotional conflict is "converted" into physical symptoms (e.g., blindness, stomach aches, paralysis) as a means of masking an underlying disturbance. Although hysteria is rare among women in America, women in Moslem countries where female sexuality is customarily repressed still experience hysteria. By contrast, women in Mideastern countries rarely 
manifest anorexia nervosa, presumably because their cultures do not sanction the display of scantily clad and thin females to the extent that U.S. culture does.

\section{Context as a Determinant of Behavior}

The meaning an individual holds for a behavior is a function of the context in which a behavior is displayed (Howell, Fox, \& Morehead, 1993). Thus, lifeguards have more meaning by the side of a pool than on a ski slope. Reading has more meaning in a library than it does in a game of soccer. In addition, few behaviors are universally inappropriate or appropriate without first considering the context in which they occur.

Running and yelling provide obvious examples. Within the context of a math lesson, these behaviors are inappropriate, whereas they would be acceptable, or possibly valued, in the context of playing basketball. A perhaps less apparent example, which nevertheless makes the same point, involves cutting someone's throat with a knife-clearly a behavior that most people would consider aberrant, especially within the context of a mugging. It would be quite appropriate, however, if someone were performing an emergency tracheotomy on a choking person. In essence, most behaviors are appropriate given some context or frame of reference.

Context also serves as stimuli that influence whether certain behaviors are or are not performed. Some stimuli exert a powerful control over behavior, whereas others have no appreciable effect (Cooper, Heron, \& Heward, 1987). For example, the ring of a phone almost always elicits the behaviors of picking up the receiver and saying "Hello." On the other hand, receiving a piece of junk mail rarely elicits the behavior of reading it.

A limitless number of contextual variables can serve as cues for youngsters to engage in any number of inappropriate behaviors. For example, being instructed to complete a math worksheet could be a cue for a student to make animal noises as a way to avoid completing the assignment or to obtain the attention of certain peers. In either case, teachers are likely to encounter resistance unless the context surrounding the behavior is analyzed and manipulated.

\section{Manipulate Context}

The word manipulation often carries with it a negative connotation- especially for adults who work with youngsters who display challenging behaviors. Manipulation, however, might not be as devious as it first appears. For example, the very process of teaching is manipulative: Teachers manipulate materials, curricula, instructional techniques, and room arrangements, to name but a few. Actually, every interaction with others could be considered manipulative because the goal is usually to elicit a response (Watzlawick, 1978).

In a communicative sense, manipulation is similar to the process of social reciprocity-mutually reinforcing interactive exchanges between individuals (Strain, Odom, \& McConnell, 1984). Therefore, adults might as well learn to manipulate effectively, relevantly, and constructively (Maag, 1991). If the word "manipulate" is unpalatable, the process can be thought of as one in which context is analyzed and modified to obtain a desired outcome.

Manipulating context can have a profound impact on reducing resistance. This assertion is based on the previous discussions of (a) how behaviors derive meaning from context, and (b) how context serves as a cue that elicits certain behaviors. Therefore, it is axiomatic that when the context surrounding a behavior changes, the meaning, purpose, and desire to engage in the behavior also changes. This arrangement is depicted in Figure 1 and is explained in the following example.

Maag (1997a) described how a teacher was confronted with a boy who refused to complete his math assignment and instead wrote the name of his school, "Norris," followed by the word "sucks" on the paper. The context, or situation, was receiving a math assignment and being instructed to write answers to the problems on the paper. The meaning the boy attached to the request was that a teacher was trying to force him to engage in an onerous task. Therefore, the request served as a cue for the student to write "Norris sucks." The purpose of writing "Norris sucks" was to obtain power and control, because no teacher can make a student write answers. The more the teacher tried to get the student to write answers, either through encouragement or admonishment, the more the challenging behavior was reinforced. The reinforcing value of obtaining power and control by getting a reaction, even a negative one, from the teacher fueled the desire to continue engaging in the inappropriate behavior.

A different picture emerged when the teacher changed the context surrounding the inappropriate behavior instead of responding in a traditional and punitive fashion (Maag, 
1997a). The teacher nonchalantly said she was sorry that his school "sucked" but that he was not being creative in his writing of the words. She enthusiastically and sincerely suggested that he turn over the paper and write "Norris sucks" repeatedly in various print styles and sizes, and forbade him from writing answers to the math problems. The boy, who began in earnest, as this request was congruent with what he wanted to do, quickly lost interest, flipped the paper back over, and began working on the math assignment.

This instruction changed the context in several ways. First, when the student began writing "Norris sucks" as requested, he was no longer being resistant but, rather, compliant. Second, to continue being resistant, he would have to begin writing the answers, because he was forbidden from doing so. Third, the teacher's attitude was that she would be pleased rather than angry if the student were to engage in the misbehavior. In all three instances the context and meaning of writing "Norris sucks" changed. This, consequently, eliminated the purpose of obtaining power and control and desire for engaging in the behavior.

\section{Functionality and Resistance}

In the previous example, the purpose for the boy writing "Norris sucks" was to obtain power and control. All behaviors-those society deems to be acceptable and unacceptable-are purposeful and serve a function for a child. Neel and Cessna (1993) used the term behavior intent to describe the relation between the behavior a child exhibited and the outcome he desired. When a child acts, even with behaviors considered to be inappropriate, he does so to achieve a result. The desired result, or outcome, can be viewed as the intent or function of the behavior. In turn, the intent of the behavior will impact on the form (i.e., appearance or topography) the behavior takes to achieve a desired outcome.

The function a behavior serves certainly can be appropriate while the form a behavior takes can be inappropriate. In the previous example, the student wrote "Norris sucks" as a way to obtain power and control. Which people do not wish to have power and control over their lives? Perhaps nowhere is this outcome so typified as in the buzz word empowerment, which is used to describe the prized American ethos of individuals being able to stand on their own and making their own way in a self-reliant, competent, and achieving fashion. Although the form of the student's behavior (writing "Norris sucks") might have been inappropriate, the purpose or intent of the behavior (power and control) was something that most people value and try to achieve in their lives.

This discussion and the previous example point to the importance of conducting functional assessment - the process of determining the intent an inappropriate behavior serves for obtaining a desired outcome and replacing that behavior with a more appropriate one that allows the youngsters to accomplish the same goal (Foster-Johnson \& Dunlap, 1993). Interventions that focus only on the form or topography of a behavior and fail to address the purpose of the behavior will often be ineffective. As long as the behavior has a powerful purpose related to it, a child will continue to perform it and continue to appear resistant.

Returning once again to the previous example, the boy wrote "Norris sucks" as a way to obtain power and control. Perhaps powerful consequences could be found that either reinforce the absence of the boy writing "Norris sucks" or punish its occurrence. Regardless, this maladaptive behavior might be eliminated only to have another similarly maladaptive behavior take its place.

Psychoanalysts refer to this phenomenon as symptom substitution, and behaviorists call it behavior covariation. To avoid these phenomena, the boy in the previous example should be taught, and reinforced for using, a replacement behavior-an appropriate behavior that serves the same function as the inappropriate behavior. Perhaps letting the boy decide how many problems he would complete would give him some power and control without having to engage in the inappropriate behavior of writing "Norris sucks."

\section{Adopting New Patterns of Behavior}

It is amazing how effectively practitioners could manage resistance if they were to perceive all their available options. Unfortunately, adults follow a careful routine without realizing they are restricting their behavior. Fisch, Weakland, and Segal (1982) suggested that, when individuals limit their options to certain ways of behaving, ordinary life difficulties become more severe because the initial problem was mishandled and remains unresolved.

These patterns often result in the application of linear interventions (Watzlawick, Weakland, \& Fisch, 1974). For example, if a student stays after school for misbehaving, the problem is presumed to have been addressed by the punishment. But what if the student misbehaves again? The linear solution would be to keep the student after school for 2 days, then 3, and so forth. This type of solution is simply "more of the same" and seldom works. If punishment were effective, it would be used less rather than more often because, by definition, it decreases behavior (Maag, 1999). Blind adherence to a punishment mentality illustrates the tremendous impact that paradigms have on adults' ability to perceive various options.

\section{Paradigms Paralysis and Resistance}

A major reason adults have difficulty managing resistance is that they are constrained by their paradigms (Maag, 1997b). A paradigm is a pattern or model for interpreting 
information. Paradigms provide people with rules and regulations that establish boundaries and explain how to be successful by solving problems within the given boundaries (Barker, 1992). People constantly are viewing the world through their paradigms-selecting from the environment the data that best fit their rules and regulations while trying to ignore the rest. As a result, what might be obvious to a person adhering to one paradigm might be totally imperceptible to a person who is holding a different paradigm.

In the case of resistance, the dominant paradigm is that resistance originates from a child, and that to reduce resistance, a child has to behave differently. This view is based on a medical-disease model of psychopathology supported by the DSM-IV criteria for Oppositional Defiant Disorder. Although Achenbach (1980) stated that evidence is insufficient to warrant a generalized medical-disease model of all behavioral disorders or to imply that these problems exist within persons as do physical diseases, this approach continues to enjoy widespread acceptance. Therefore, most interventions for managing resistance focus on changing a child's behavior.

Information about managing resistance that does not conform to this paradigm is not acknowledged and used. Barker (1992) coined the term paradigm paralysis - a condition of terminal certainty - to characterize the propensity of people to see only that for which they are looking. Yet, not everything people see is the way they see it. For example, fleeting impressions of criminal behavior are embellished by individuals into complete accounts that they believe to be "true" based on their emotions and prejudices (Loftus, 1979). People also have trouble expanding their paradigms, as the movement would threaten their existing knowledge-base. As Scarr (1985) stated: "Each of us has our own reality of which we try to persuade others" (p. 499).

\section{Overcoming Limitations}

Paradigm paralysis prevents practitioners from abandoning their preconceived notions about what they "should" do or say to a child and expanding their perspective to consider alternative options. The cure for paradigm paralysis is for practitioners to be comprehensive and unrestricting in their behavior. In this way, they are more likely to access knowledge and skills in their repertoire that are not otherwise perceived as options for managing resistance.

What practitioners could do if they were to perceive all of their available options would be amazing. Individuals average an estimated one billion experiences in any 20-year period; with a great deal of difficulty individuals are aware of $40 \%$ of their total experiences; and of that $40 \%$, individuals might actually recall only $1 \%$ (Miller, 1986). Practitioners have much more knowledge on how to manage resistance then they let themselves know (Maag, in press).
Nevertheless, accessing past knowledge and experiences for managing resistance requires overcoming limitations.

Milton Erickson, an unorthodox and controversial psychiatrist, was an expert at allowing himself to be unfettered by convention. Rossi, Ryan, and Sharp (1983) described how Erickson walked into a room to provide a consultation for a patient with catatonic schizophrenia sitting in a chair. Several psychiatrists were standing nearby discussing various conventional psychiatric interventions such as the use of psychotropic medication and electroconvulsive shock therapy before asking Erickson for his recommendation. Without hesitation, Erickson walked up to the patient and stomped on his feet several times. The patient immediately snapped out of his catatonic state.

The point to be made here is not that foot stomping would result in long-term change, or that it is the intervention of choice for managing resistance but, rather, that many potential options are available if professionals only would overcome their limitations and access other areas of experience. There is a profound truth when Erickson would tell professionals who attended his seminars that it was important to understand the difference between knowledge and knowing (Haley, 1993).

\section{TECHNIQUES FOR MANAGING RESISTANCE}

A limitless number of techniques can be used to manage resistance, and describing the bulk of them certainly would be beyond the score of this article. Some techniques-such as reinforcing appropriate behavior or the absence of inappropriate behavior-are conventional. Other techniquessuch as the use of paradoxical directives-are more controversial. Managing resistance, however, is much more than the simple application of traditional or novel intervention techniques. It requires understanding and putting into practice the three foundational precises described previously:

1. Analyzing and manipulating context surrounding a behavior so as to change its meaning, purpose, and the child's desire to perform it.

2. Identifying the function that maladaptive behavior serves and providing the child with an appropriate behavior that serves the same purpose.

3. Practitioners' adopting new patterns of responding to children by being comprehensive and unfettered by convention.

Without considering these three foundational precises, most interventions for managing resistance will be less than optimally effective. In addition, there is no one panacea for resistance. Consequently, practitioners who have open minds, do not take children's behaviors personally, and are 
not afraid to try something different will have greater success in managing resistance than practitioners who suffer from paradigm paralysis.

There is no such thing as a useless intervention. Even interventions that do not produce a desired effect can provide practitioners with important information. This last statement is congruent with a basic operation of functional assessment: Interventions are implemented to test a hypothesis about the intent a behavior serves (Larson \& Maag, 1998). For example, a hypothesis that a student is yelling in class to get a peer's attention might be tested by having the two students work together. If yelling decreases, the hypothesis is confirmed. If yelling continues, then information is obtained that the intent of the behavior may not have been attention. In either case, valuable information is obtained. Therefore, managing resistance requires living the axiom that if something is not working, try something else. Trying and failing is not failing. It is assessment. Never trying is failing (Maag, in press).

Most of the interventions presented in this section reflect the general logic of the three foundational precis. Therefore, overlap and redundancy will be apparent throughout the discussion of many of the intervention techniques. Previous examples will be alluded to several times. This redundancy is desirable because it reinforces the three foundational precis and provides a framework for managing resistance.

Six interventions are described in this section. The first three approaches - scrambling routine, inconvenience, and paradoxical directives - focus on analyzing and manipulating context. The distinction between these three approaches is often blurry, although some important nuances exist. Both of these aspects will become apparent as the interventions and examples are presented.

The next three interventions-embedding instructions, behavioral momentum, and reframing - are more of a potpourri. Nevertheless, they share the commonalities of adults acknowledging resistance by observing and using children's behaviors as a way to accomplish a desired outcome. This commonalty follows a basic tenant when working with anyone with challenging behaviors: Develop interventions based on what the person presents.

\section{Scrambling Routine}

The performance of a series of behaviors may be conceptualized in terms of a stimulus-response chain (Malott, Whaley, \& Malott, 1997). A stimulus elicits a response that, in turn, becomes a cue to perform another behavior. The approach of scrambling routine is sometimes referred to as sequence confusion (Lankton, 1985). For example, preparing to take a math quiz might be a cue for a student to feel anxious. Anxiety then becomes a cue for the student to begin crying. Crying, in turn, becomes a cue for the student to run out of the room, and so forth. If the stimulus-response chain is broken or "scrambled," the student no longer can perform the behavior as it was previously.

For example, instructing the student to "feel anxious" 15 minutes prior to taking a math quiz changes the context because the stimulus-response sequence was switched. In this example, the intervention also was paradoxical (Simon \& Vetter-Zemitzsch, 1985). If the student brings on anxiety, he has proof that anxiety is under his control. If he refuses to bring on anxiety, he also has proof that anxiety is under his control, because he was able to avoid experiencing it.

More than three decades ago, Ayllon (1963) used a sequence scrambling approach to treat a hospitalized female psychiatric patient who hoarded and stored large numbers of towels in her room. The treatment consisted of having the nurses go into the patient's room and every day hand her more towels. After accumulating more than 600 towels, the patient began to take a few out of her room. At that point, no more towels were handed to her. Over the course of a year, the average number of towels in her room decreased to one to five per week, as compared with 13 to 29 before the intervention. Providing the patient with several towels daily represented a new stimulus. She could not continue her normal way of behaving because she eventually received more towels than she was hoarding. Consequently, the context surrounding the behavior was changed, which, in turn, changed the meaning she attached to hoarding, the purpose this behavior served, and her desire to continue it.

The intervention that Ayllon (1963) used made it impossible for the patient to go through the same sequence repeatedly, as she had done previously during her hospitalization. She apparently had learned to tolerate accumulating a set amount of towels. The intervention succeeded in making the patient's tolerance level intolerable because the nurses made her go beyond it. The method of reverse patterning is not new. Adler (1931) metaphorically noted that therapy was like spitting in someone's soup-the person could continue to eat it but he would not like it.

There are two additional considerations if the intervention that Ayllon (1963) used was to have resulted in durable behavior change. First, the purpose of hoarding towels had to be identified. The patient possibly hoarded to obtain power and control, attention, or both. Therefore, she would have to be taught, and reinforced for using, a replacement behavior. For example, perhaps the patient could have helped the staff decide on her daily schedule and provided input on when she was ready for a home pass. These behaviors would permit her to obtain some power and control in a setting-locked psychiatric unit-which typically did not promote and reinforce patient autonomy and independent thinking in the early 1960s. If hoarding was performed to 
obtain attention, the patient might be taught to ask for assistance or to request that a staff member talk with her at appropriate times. In either case, the absence of teaching, and reinforcing the use of, a replacement behavior would simply result in the patient displaying other inappropriate behaviors to obtain the desired outcomes. Second, when the nurses gave her more towels, they should have displayed an attitude toward the patient of being pleased that she now had an opportunity to get really good at hoarding. In this way, the nurses would have eliminated any power and control value the patient might have previously obtained by seeing them angry and frustrated at her hoarding. This last observation is congruent with the attitude displayed by the teacher in getting the student to write "Norris sucks" in a previous example.

\section{Inconvenience}

Many parents have used the technique of inconvenience to get siblings to stop arguing: They are told to argue outside when it is dark or cold. Arguing is permitted, but it becomes inconvenient. Therapists often have couples use this same technique by instructing them to argue in the garage or caranywhere that would be inconvenient.

Milton Erickson used this technique with Kristina, one of his daughters (Zeig, 1985). Kristina recounted how, as a child, she and her sister would be in bed sleeping and their father would come in the room and flip on the lights in the middle of the night. He would tell Kristina that he had noticed that the wheelbarrow and rake she had been using that day were in the middle of the backyard instead of in the garage where they belonged. Erickson told Kristina she would have to put them away. Still half asleep, she would drag herself out of bed, trudge into the backyard, put away the tools, and go back to bed while all along her sister was lamenting how Kristina's forgetfulness resulted in a disrupted night's sleep. Kristina seldom forgot, because she did not want to get up at midnight.

Erickson's use of inconvenience meant that his daughter was never angry at him. For one thing, she knew that she was supposed to put tools away after using them. For another, Erickson did not present the task as a punishment. Rather, he often was apologetic about not noticing earlier in the day that the tools were left outside. This attitude helps avoid power struggles. A child has little to resist when the adult presents the task as his fault and apologizes sincerely.

The previous allusion to the student who was required to write "Norris sucks" many times to get him to stop engaging in this behavior is a type of inconvenience called negative practice, which requires a child to repeatedly engage in the inappropriate behavior. For example, Azrin, Nunn, and Frantz (1980) treated the nervous tics of 22 institutionalized patients by requiring them to perform the tic in front of a mirror for 30-second periods during a 1-hour session while simultaneously saying to themselves, "This is what I am not supposed to do."

Before proceeding with the present discussion, a note of caution is necessary. Negative practice should not be used for behaviors that are dangerous to self or others (Maag, 1999). For example, an adolescent who carves on her arm with a knife and a child who hits peers should not be instructed to repeatedly engage in these behaviors.

Some professionals also object to the use of negative practice on the grounds that children should be taught appropriate behaviors and that negative practice only serves to focus undue attention on the misbehavior. These criticisms are valid. Negative practice, however, serves an important function: It could change the context surrounding the inappropriate behavior, which, in turn, changes the meaning, purpose, and desire to perform it. In addition, with the right attitude, teachers can fairly easily get children to participate in negative practice because children are being instructed to engage in a behavior they want to perform, as evidenced in the case of the boy who wrote "Norris sucks."

Here is another example of how Erickson used negative practice with one of his daughters:

\footnotetext{
My daughter came home from grade school and said, "Daddy, all the girls in school bite their nails, and I want to be in style too."

I said, "Well, you certainly ought to be in style. I think style is very important for girls. You are way behind the girls. They have had a lot of practice. So I think the best way for you to catch up with the girls is to make sure you bite your nails enough each day. Now I think if you bite your nails for fifteen minutes three times a day, every day (I'll furnish a clock) at exactly such-and-such an hour, you can catch up."

She began enthusiastically at first. Then she began beginning late and quitting early, and one day she said, "Daddy, I'm going to start a new style at school-long nails." (Rosen, 1982, p. 145)
}

In this example, Erickson joined in his daughter's frame of reference and agreed that being in style was important. This "joining the child" is a prerequisite for getting compliance with the request. If Erickson had said, "Young lady, biting nails is a bad habit, and you will be punished by having to spend time every day biting your nails to show you just how bad it is," his daughter most likely would have become resistant. This approach points to an important consideration when using negative practice: The behavior to be practiced should be one that a child cannot legitimately object to (Haley, 1984). His daughter wanted to bite her nails and the boy in a previous example wanted to write "Norris sucks." Both children were simply instructed, in an encouraging way, to do more of the behaviors. 
Negative practice requires little advanced preparation. The most difficult part of negative practice is for a practitioner to convey to a child that he or she is not angered but, rather, pleased that the child has the opportunity for practice. This attitude goes against the typical mindset of most adults. Yet, adopting it, and having a behavior for which a child cannot legitimately object to performing, will add greatly to adults' abilities to manage resistance with minimal effort. Otherwise, negative practice becomes punitive and meaningless.

\section{Paradoxical Directives}

Paradoxical directives seem to defy logic. They convey to children that they can change by remaining unchanged. The idea behind working paradoxically is for adults never to fight with children. When adults accept a child's resistance, the child is caught in a position in which resistance becomes cooperation. Haley (1973) described how Erickson would make this point by using an analogy of a person who wants to change the course of a river:

\footnotetext{
If he opposes the river by trying to block it, the river will merely go over and around him. But if he accepts the force of the river and diverts it in a new direction, the force of the river will cut a new channel. (p. 24)
}

This point, and the analogy that illustrated it, is an important one that deserves elaboration before describing the various types of paradoxical techniques.

Too often, intentionally or unintentionally, adults attempt to inculcate children with ways of looking at, and dealing with, the world that has worked well for them but that may be clumsy and inappropriate from children's perspectives. Adults expect children to accept authority. Trying to lecture or otherwise force a child to comply with an adult's version of the world can result in resistance (Maag, 1997b). No two people are alike, and no two people understand the same sentence the same way. Erickson (1962) believed that individuals bring with them a model of the world that is as unique as their thumbprints. Therefore, to manage resistance effectively, adults must not try to fit children to an adult concept of what they should be. Instead, adults should join children in their frames of reference.

To determine children's frames of reference is not easy because they have their own unique experiences and have organized those experiences into an equally unique set of judgments about the nature of the world and a set of rules by which to live relative to the context in which that view is operating (Gordon \& Meyers-Anderson, 1981). Accessing a child's model of the world is exacerbated because it is not accessible to direct observation. Therefore, one way to join children's frames of reference is to instruct them to do what they are doing already and then interject some difference. Paradoxical directives provide ways of accomplishing this goal.
Paradoxical directives can focus on either encouraging a child to produce the maladaptive behavior at will (compliance-based) or avoiding trying to behave appropriately (defiance-based) (Simon \& Vetter-Zemitzsch, 1985). Both types of paradoxes are based on analyzing and manipulating the context surrounding a behavior. The specific techniques share many similarities with approaches for scrambling routine and inconvenience, described previously.

\section{Compliance-based Paradoxes}

Compliance-based paradoxes communicate the message that, to reduce an inappropriate behavior, a child may keep it. The idea is to make an uncontrollable behavior occur voluntarily. Because the behavior would occur anyway, a child would be in a better position to predict its occurrence. Therefore, the process that perpetuates the problem behavior is interrupted; a child cannot continue the usual ways of trying to prevent the behavior. The student who was instructed to bring on anxiety 15 minutes prior to taking a math quiz is an example of a compliance-based paradox. It also made use of scheduling - having a child express a behavior in different locations, durations, or times before it occurs spontaneously (Rohrbaugh, Tennen, Press, \& White, 1981).

For example, two children who argue could be instructed to "argue" for 5 minutes at various times throughout the day. If the children adhere to the request, they are being compliant. If they refuse to follow the direction, they also are being compliant because, by not arguing, the desired outcome is attained.

Two other approaches for using compliance-based paradoxes involve adding either a negative or a positive aspect to a behavior. The examples of pattern scrambling and inconvenience described previously are techniques for adding a negative aspect to a behavior. These approaches focus on making the performance of a behavior into an ordeal. Haley (1984) described four characteristics of a good ordeal:

1. The ordeal should cause distress equal to or greater than that caused by the troubling behavior. For example, a student who is distressed by compulsively sharpening pencils 25 times a day could be required to sharpen pencils 50 times a day at a pencil sharpener in a remote part of the school.

2. The ordeal should be good for the person. For example, requiring an adolescent who wants to quit smoking to keep a pack of cigarettes in a place that is accessible only by walking 1 mile would provide him with exercise.

3. The ordeal must be something the person can do and to which he or she cannot legitimately object. For 
example, the boy who wrote "Norris sucks" agreed to write it because it was a behavior in which he could, and wanted to, engage.

4. The ordeal should not harm the person or anyone else. For example, a student who kicks other students or cuts himself or herself with a knife should not be required to engage in more of these behaviors.

The second approach involves adding a positive aspect to a behavior. This approach, known as reframing, involves modifying a person's perceptions or views of a problem behavior. Context and meaning reframing are described later in this article.

\section{Defiance-based Paradoxes}

Defiance-based paradoxes convey to children that, to change, they have to stay the same or give up. The idea here is to have a child oppose carrying out the directive and, by so doing, the child is being compliant. Maag (1997a) provided an example of using a defiance-based paradox with a student who threw his book on the floor and refused to pick it up when requested. He told the teacher, "I won't pick up the book and you can't make me-nobody can make me." The teacher countered by saying, "You're right, I can't make you pick up that book. I can't even make you move that book one inch. And you won't move the book one foot . . . you certainly won't move the book closer to your desk. And I refuse to let you put the book on your desk!" The student either moves the book, continuing to be resistant, in which case the desired outcome is reached, or he refuses to move the book, thereby complying with the teacher's direction. Although in the latter case the book still remained on the floor, compliance was established, which builds momentum for establishing compliance to other directions.

Defiance-based paradoxes can be delivered in at least three ways (Rohrbaugh et al., 1981). First, children can be instructed to delay changing their behaviors by having them move more slowly than they expect. For example, an adult could say "Today it is important not to do anything to improve your behavior." Second, adults can forbid children from changing their behaviors. For example, an adult could say, "to find out how bad your behavior is, just give in to it and let it happen" or, "I don't want you to be polite today."

A particularly effective way to forbid change is to initially tell a noncompliant student, "It is very important that today you follow my direction to the letter." These types of students typically know that teachers have been unsuccessful in getting them to comply and are highly reinforced by power and control. Therefore, they should be enthusiastically invested in proving that no teacher can get them to follow a direction. The teacher then says, "I don't want you to complete any work today." Initially telling the student how important it is to comply is a way of encouraging resistance and thereby engendering compliance. As George Bernard Shaw said, "Don't be afraid of opposition—remember a kite rises against the wind, not with it."

A third variation, which is more extreme, is to declare hopelessness - to predict that change is impossible. For example, an adult could say, "I think it really is impossible for you to finish your homework."

\section{Cautions When Working Paradoxically}

Paradoxical—or any other names for context manipulation-techniques are powerful and can be used to engender compliance for a variety of behaviors and situations. They are no panacea, however, and there are several cautions when working paradoxically. First, they should not be used with youngsters who have strong self-doubts or pose a danger to themselves or others (Rohrbaugh et al., 1981). Second, paradoxical techniques will not work well with individuals who have antisocial or paranoid personalities who will either change the task to fit their own needs or become suspicious (Cormier \& Cormier, 1985). Third, because paradoxical techniques are unorthodox and rely on some deception, they seem to violate the ethical tenet of informing individuals of the treatment rationale and technique (Shelton \& Levy, 1981). Birchler (1981), however, asserted that if a paradoxical technique is based on an accurate functional analysis, an individual can be told openly why a task is being assigned.

In addition to these cautions, paradoxical interventions often are complex and require ample skill and energy to implement effectively (Cormier \& Cormier, 1985). They should not be presented or used in a cavalier fashionespecially by individuals who have little training in their use. On the other hand, many adults - teachers, therapists, and laypersons alike-have intuitively used paradoxical techniques successfully and have shared them with others (Christian, 1997). This last comment should be placed within in a context that could have ethical and legal ramifications.

For example, a teacher might set up a place and times for a student with a repeatedly foul mouth to "practice swearing." Although this technique might be effective, the student's parents might find it objectionable and, consequently, pursue legal action. Similarly, Cormier and Cormier (1985) suggested that a jury might have a difficult time understanding why a therapist would tell an insomniac to "try to stay awake at night."

The impact of these potential problems can be lessened if practitioners engage in functional assessment either prior to, or during, the time when they are implementing paradoxical interventions. In this capacity, paradoxical techniques can be used to test hypotheses regarding the intent of a behavior. Maag (1997a) described the use of the "do-nothing" chair 
for students who are passive-aggressive. When a student is passively doing nothing instead of working on an assignment, the teacher enthusiastically encourages the student to go to the "do-nothing chair" to "practice getting really good at doing nothing."

This paradox makes use of scheduling and can be used to test three possible hypotheses regarding the function of doing nothing. If the desired student outcome is power and control, the student should refuse to go to the "do-nothing" chair because he would be compliant by going there. The do-nothing chair will work elegantly when the desired outcome is power or control. It will not work if the desired outcome is escape or avoidance. For example, if a student is sitting passively because he either does not have the requisite skills to do the task independently or finds the task boring, the do-nothing chair will provide him with a way to escape or avoid thereby reinforcing noncompliance.

This hypothesis can be tested further by giving the student an easy, high-interest activity instead of the independent seatwork assignment. If the student engages in the easy, high-interest activity, the teacher has obtained information that passivity can serve an escape or avoidance function because passivity was eliminated when the opportunity to engage in an alternative high-interest activity was presented. If, however, the student continues to do nothing when he is presented with an easy, high-interest activity, the desired outcome might be attention. In this scenario, the student might believe that going to the "do-nothing" chair is a "badge of honor" in the same way that some students enjoy going to time-out: They can impress their peers.

\section{Embedding Instructions}

Erickson used embedding instructions as a method to induce hypnotic trance (Bandler \& Grinder, 1975). It has many nonhypnotic applications for managing resistance. The essence of this technique is to instruct children to do what they are doing already while interspersing the request for a desired behavior. For example, a teacher could embed the following instruction to a student: "Mary, as you shuffle your papers, open your math book to page eighteen while you are talking to Susie." In this situation, Mary is engaging in two undesirable behaviors: shuffling her papers and talking to Susie. This instruction embeds three separate tasks, two of which Mary is performing already. The part of the instruction for which her teacher is trying to get compliance is opening the math book to page 18 . If the instructions were separated, Mary could easily refuse one or all of them. But a refusal when the tasks are combined into a single instruction means what? That Mary will not shuffle her papers? That she will not open her book? That she will not talk to Susie?

The very extent of the effort required to identify what one is refusing is a deterrent to refusal in itself (Bandler \&
Grinder, 1975). Nor can a refusal of the entire instruction be offered comfortably. Mary can easily say "no" to each of the single tasks, but she cannot say "no" to the combined task because, if she is shuffling her papers, she must open her book immediately and talk to Susie. Hence, Mary might prefer to perform the combined task unwillingly rather than to put forth the effort to analyze the instruction minutely. Although this reasoning is specious, it is the emotional reasoning common in daily life, and daily living is not an exercise in logic.

Embedding instructions has one last subtle, but important facet. Embedding requires teachers to instruct students to do what they are doing already. This aspect of embedding instructions is similar to paradoxical directives and, as such, can change the context surrounding the behavior, which, in turn, changes the meaning, purpose, and desire to perform it. The subtle and therapeutic value of telling a student to do what she is doing already immediately engenders compliance. If Mary continues to shuffle her papers and talk to Suzie after being instructed to do so, she is being compliant. When a teacher gets compliance in one area, getting compliance in another area becomes easier. On the other hand, if Mary resists this instruction and stops shuffling her papers and talking to Suzie she is also being compliant.

Practitioners voice two common concerns about the use of embedding instructions (Maag, 1997b). The first is the one addressed previously when describing overcorrection: What if it does not work? To elaborate on that answer, a technique that does not work is not synonymous with being a "bad" teacher, therapist, clinician, or parent. It simply means that the technique did not produce the desired outcome. At worst, the failure of a technique means to try something else. At best, it represents a way to collect assessment information.

\section{Behavioral Momentum}

Behavior momentum works by instructing a student to engage in two or three behaviors that a teacher knows a student wants to naturally perform: making high-probability requests. Once a student is performing the desired highprobability behavior, the teacher makes the desired lowprobability request. A low-probability request represents a behavior that a student does not want to performtypically the behaviors associated with following a teacher's instructions.

For example, a teacher might request that a student tack pictures on a bulletin board (high-probability behavior) and follow it with the instruction to throw away trash (lowprobability behavior), which, in turn, could be followed by an instruction to knock off the chalk from two erasers over the trash can (high-probability behavior). 
The idea behind this approach is to build momentum toward compliance by first getting a child to do a series of desired behaviors. When the third instruction (representing a second high-probability behavior) is added, behavioral momentum begins to resemble an embedded instruction.

Rhode, Jenson, and Revis (1995, p. 79) have provided guidelines for implementing behavioral momentum.

1. Select a series of behaviors that a student already likes to do. (when the teacher requests the behaviors, the student is at least $70 \%$ likely to do what the teacher requests).

2. Ask the student to do several of the likely behaviors before asking the student to do the behavior he or she does not want to do (the unlikely behaviors). For example:

a. "Tom, will you help me hand out the papers?"

b. "Thanks Tom. Now please help me straighten the chairs."

c. "Now Tom, please sit down and do your math assignment."

3. Ask for two or three likely behaviors before asking for the unlikely behavior, to greatly enhance the momentum effect. Asking even one likely behavior before the unlikely behavior can help, such as: "Tom, please help me erase the board (likely behavior). Now Tom, please write your spelling word on the board (unlikely behavior)."

4. Engineer behavior momentum into the classroom schedule. Instead of starting with unlikely activities such as a review of the previous day's problems, a difficult academic assignment, or a calendar review, start with likely-behavior games such as Simon Says, Seven-Up, team guess of a teacher's selected mystery animal, reading a high interest story, charades, and the like. Follow this activity with less likely activities (such as academic, problem review).

Behavioral momentum shares a similarity with embedding instructions in that they both link preferred behaviors with disliked behaviors. They are different in that with embedding instructions, children are directed first to do what they are doing already, whereas with behavioral momentum, a behavior that currently is not being performed, but one that has a high probability of occurring, is requested first. Identifying high-probability behaviors is fairly easy. They are the behaviors in which teachers either observe students doing when they have free access to do what they like (Premack principle) or those students are constantly requesting the opportunity to perform. A student's continually asking a teacher to knock the chalk off erasers is an example. Embedding instructions has a somewhat greater likelihood of obtaining a desired response because children cannot refuse to do what they are doing already. With behavioral momentum, however, there is a chance that a student will not want to perform, a highprobability behavior upon request, for whatever reason.

\section{Reframing}

The meaning that any situation and corresponding behaviors have depends on the frame of reference in which they are perceived. Changing an individual's frame of reference changes the meaning and, consequently, the purpose and desire to engage in a behavior. An approach for accomplishing this goal, called reframing, involves modifying a person's perceptions or views of a situation or behavior (Watzlawick, Weakland, \& Fisch, 1974).

Reframing is not new to the therapeutic process. Teachers who try to get students to "think about things differently" or to "see a new point of view" or to "take other factors into consideration" are attempting to reframe events to get students to respond differently to them. Examples of reframing appear in many fairy tales and fables: The strange-looking chick seems to be an ugly duckling who turns out to be a swan, and Rudolf the Reindeer's funny-looking red nose becomes a useful beacon for guiding Santa's sleigh on a foggy night (Bandler \& Grinder, 1982). Therapeutically, reframing focuses on the meaning of a behavior or the context in which a behavior occurs.

\section{Meaning reframing}

Meaning reframing involves challenging the purpose that a child has assigned to a problem behavior. Usually, the longer a child attaches specific meaning to a behavior, the more necessary the behavior itself becomes for maintaining consistency and predictability. The longer a meaning is attached to a behavior, the more a child is likely to see things in only one way or from one perspective. Meaning reframing provides children with alternative ways to view a problem behavior without directly challenging the behavior itself and by loosening an entrenched frame of reference. For example, a child's "stubbornness" might be reframed as "independence"; or "greediness" might be reframed as "ambition."

The main goal of meaning reframing is to help people make sense out of their ongoing experiences with respect to their personal models of the world. Gordon and MeyersAnderson (1981) provided the following example of how Erickson used meaning reframing to heip a client with insomnia:

Insomnia is your misuse of time . . those are bonus hours. While you are awake in bed, start thinking about all of the pleasant things that you want to do, that you have done, and 
you'll find that they are bonus hours, not insomnia hours. So you'll find yourself with thoughts of something pleasant, your body will become accustomed to the bed, and you'll go to sleep. (p. 58)

"Insomnia is your misuse of time . . those are bonus hours." With those few words, Erickson completely reorients the client with respect to the problem situation so that what has seemed to be an encumbrance for so long is suddenly revealed as a mitigation. This contrary interpretation of insomnia is much more than simple idea-play. This shift in perspective is what made it possible for Erickson to help the client to more useful bedtime experiences.

The author used a meaning reframe with a 17-year-old boy who had been referred to his private practice after being suspended three times for fighting. The boy explained that his fights occurred because other guys were talking to his ex-girlfriends. When asked what this meant, he replied that the boys were "disrespecting" him. The author and the boy then discussed, with grandiosity, the boy's prowess in acquiring beautiful girlfriends, how he always broke up with them-he never got dumped-and how any girl would be thrilled to date him. The author then turned to the boy and said, "Maybe when some guy is talking to an ex-girlfriend, that means he respects your taste in women."

This meaning reframe was acceptable to the boy for two reasons. First, it focused on the importance the boy placed on being "disrespected" by reorienting the interaction into "respect." Second, the reframe fed into the predictable and exaggerated adolescent male ego regarding his perceived desirability to females. In the future, seeing some guy talk to an ex-girlfriend might serve to remind the boy how desirable he is to females, thereby lessening the urge to respond aggressively.

\section{Context Reframing}

Besides reframing the meaning of a behavior, the context in which a problem behavior occurs can be reoriented. Reframing the context helps individuals explore and decide when, where, and with whom a given problem behavior is useful or appropriate (Bandler \& Grinder, 1982). In essence, context reframing helps individuals answer the question, "In what place in your life is a particular behavior useful and appropriate?"

Context reframing is based on the assumption that every behavior is useful in some, but not all, contexts or situations. Thus, when a student says, "I won't do my assignment," a context reframe could be, "In what situations, or with what people, is it useful or even helpful not to do what an adult asks?" Two situations immediately come to mind: if a child is being solicited by another child to experiment with drugs or if an adult stranger is trying to convince a child to get into his car against the child's will.
Context reframing can be used when a teacher becomes exasperated with a student's behavior - a situation that could easily lead to power struggles. For example, the author encountered a well intentioned but highly-rigid teacher. The teacher's complaint was that one student in her class was too stubborn and did not follow directions. At one time when she made this complaint, the author looked at her and said, "You're a woman who has done very well in life. You have your master's degree, have raised three children, begun a second career as a teacher, and are the team leader for your department. You obviously have some tenacity, don't you?" After the teacher replied "yes," the author got to the crux of the context reframe: "Well, there is a part of you that has allowed you to be able to get where you are, and to be a good teacher. And sometimes you have to refuse people things that you would like to be able to give them because you know if you did, something bad would happen later on. There is obviously a part of you that's been stubborn enough to really protect yourself in very important ways."

Ignoring the teacher's protests that this type of behavior cannot be tolerated in students, the author went on, "Now, I want you to look at this student tomorrow and to realize beyond a doubt that you've helped him become stubborn and how to stand up for himself, and that this is something priceless. This gift that you've given to him is something that can't be bought, and it's something that may save his life. Imagine how valuable that will be when he is approached by peers to drink and drive."

In this example, the teacher initially perceived the student's stubborness as being a bad trait in the context of the classroom. It becomes good, however, in the context of becoming a teacher and in the context of peers trying to get the student to engage in dangerous behavior. The context the teacher had used to evaluate the student's behavior was changed. His behavior of being stubborn with her is no longer seen as his fighting with her. Instead, it can be viewed as a professional accomplishment; she had taught him to protect himself from engaging in dangerous behavior.

The pattern that is similar in both context and meaning reframing is that every experience and every behavior in the world is appropriate, given some context or frame of reference. Much of the behavior that children exhibit that often is labeled as resistance indicates that their context is internal and is based on past experiences. When, for example, a teacher says to a student, "You really did a great job completing your math problems," and the student responds with, "Fine, but I don't really care and I didn't do that good a job, so I wish you wouldn't lie to me," that is a fairly good indication that the student is operating out of a unique internal frame of reference.

Upon further exploration, it may become apparent that, from past experience, the student takes a compliment to 
mean that he will have to do more work or that teacher demands will increase in the future. The ability to deal with resistance often rests with adults realizing that what seems bizarre and inappropriate is simply a statement about the failure to appreciate the context on which a behavior is based.

\section{CONCLUSION}

There is no mystery as to why children say no. The behaviors serve an adaptive function. All too often, practitioners focus solely on the form a behavior takes and ignore its function and the context in which it is displayed. The tendency to ignore function and context is most evident with behaviors perceived to be aberrant. Serial murderer Jeffrey Dahmer killed young men, chopped up their body parts, and saved them in containers. One of the reasons he gave for engaging in the third behavior was that he did not want his victims to leave him. This behavior compensated for his having few longlasting relationships with others. Although the behavior was highly abnormal, the function it servedlongevity in relationships-was normal (Maag, 1997c).

Context is equally ignored when reacting to deviant behavior. A 7-year-old attending public school in Denver mistakenly grabbed her mother's lunch sack on her way to school. At lunch time, she pulled out of the sack a sandwich, chips, an apple, and a knife. She was summarily expelled from school for carrying a weapon. Her mother's and her lunch sacks had been inadvertently switched. The knife was to have been used by her mother to pare the apple. The context surrounding this behavior was ignored, although the girl later was reinstated in school.

These two examples point out that there are different ways of looking at situations and behaviors. Managing resistance does not have to be a massive job. It can be accomplished by using a variety of techniques. Children's behaviors usually give adults clues on how to manage resistance. Unfortunately, adults often have closed minds and fail to pick up on these clues, instead responding with linear interventions that seldom work.

If an intervention is not working, practitioners should try something else. Grinder and Bandler (1981) insightfully noted that the meaning of any communication is the response it elicits. Practitioners usually know what to do but do not always know that they know. Introducing variety and richness into children's lives by understanding and analyzing context, determining the relations between noncompliant behaviors and the functions they serve, and being comprehensive and unrestricting in their behavior will help adults break up the rigid patterns of responding necessary for managing resistance effectively.

\section{REFERENCES}

Achenbach, T. M. (1980). DSM-III in light of empirical research on the classification of child psychopathology. Journal of the American Academy of Child Psychiatry, 19, 395-412.

Adler, A. (1931). What life should mean to you. Boston: Little, Brown.

American Psychiatric Association. (1980). Diagnostic and statistical manual of mental disorders (3d ed.). Washington, DC: APA.

American Psychiatric Association. (1987). Diagnostic and statistical manual of mental disorders (3d ed. rev). Washington, DC: APA.

American Psychiatric Association. (1994). Diagnostic and statistical manual of mental disorders (4th ed.). Washington, DC: APS.

Ayllon, T. (1963). Intensive treatment of psychotic behavior by stimulus satiation and food reinforcement. Behavior Research \& Therapy, 1, 53-61.

Azrin, N.H., Nunn, R.G., \& Frantz, S.E. (1980). Habit reversal vs. negative practice treatment of nervous tics. Behavior Therapy, 11, 169-178.

Bandler, R., \& Grinder, J. (1975). Patterns of the hypnotic techniques of Milton H. Erickson, M.D: Volume I. Capitola, CA: Meta.

Bandler, R., \& Grinder, J. (1982). Reframing: Neuro-linguistic programming and the transformation of meaning. Moab, UT: Real People Press.

Barker, J. A. (1992). Paradigms: The business of discovering the future. New York: HarperCollins.

Birchler, G. (1981). Paradox and behavioral marital therapy. In A.S. Gurman (Ed.), Questions and answers in the practice of family therapy (Vol. 1, pp. 123-127). New York: Brunner/Mazel.

Christian, B.T. (1997). Outrageous behavior-mod: Handbook of strategic interventions for managing impossible students. Silver City, NM: Author.

Clinard, M.B., \& Meier, R.F. (1995). Sociology of deviant behavior (9th ed.). Fort Worth, TX: Harcourt Brace.

Cooper, J.O., Heron, T.E., \& Heward, W.L. (1987). Applied behavior analysis. Columbus, $\mathrm{OH}$ : Merrill.

Cormier, W.H., \& Cormier, L.S. (1985). Interviewing strategies for helpers: Fundamental skills and cognitive behavioral interventions ( $2 \mathrm{~d}$ ed.). Monterey, CA: Brooks/ Cole.

Erickson, M.H. (1962). The identification of a secure reality. Family Process, 1, 294-303.

Fisch, R., Weakland, J., \& Segal, L. (1982). The tactics of change: Doing therapy briefly. San Francisco: Jossey-Bass.

Forehand, R. (1977). Child noncompliance to parental requests: Behavioral analysis and treatment. In M. Hersen, 
R.M. Eisler, \& P.M. Miller (Eds.), Progress in behavior modification (Vol. 5, pp. 111-147). New York: Academic Press.

Foster-Johnson, L., \& Dunlap, G. (1993). Using functional assessment to develop effective, individualized interventions for challenging behavior. Teaching Exceptional Children, 25(3), 44-50.

Gelles, R.J., \& Cornell, C.P. (1985). Intimate violence in families. Beverly Hills, CA: Sage.

Gordon, D., \& Meyers-Anderson, M. (1981). Phoenix: Therapeutic patterns of Milton H. Erickson. Cupertino, CA: Meta.

Grinder, J., \& Bandler, R. (1981). Trance-formations: Neuro-linguistic programming and the structure of hypnosis. Mohab, UT: Real People Press.

Haley, J. (1984). Ordeal therapy. San Francisco, CA: Jossey-Bass.

Haley, J. (1993). Jay Haley on Milton H. Erickson. New York: Brunner/Mazel.

Howell, K.W., Fox, S.L., \& Morehead, M.K. (1993). Curriculum-based evaluation: Teaching and decision making ( $2 \mathrm{~d}$ ed.). Pacific Grove, CA: Brooks/Cole.

Johnston, J.M., \& Pennypacker, H.S. (1993). Strategies and tactics for human behavioral research (2d ed.). Hillsdale, NJ: Lawrence Erlbaum.

Kazdin, A.E. (1989). Conduct and oppositional disorders. In C.G. Last \& M. Hersen (Eds.), Handbook of child psychiatric diagnosis (pp. 129-155). New York: Wiley.

Kuczynski, L., Kochanska, G., Radke-Yarrow, M., \& Girnius-Brown, O. (1987). A developmental interpretation of young children's noncompliance. Developmental Psychology, 23, 779-806.

Lankton, C.H. (1985). Generative change: Beyond symptomatic relief. In J.K. Zeig (Ed.), Ericksonian psychotherapy (Vol. 1, pp. 137-170). New York: Brunner/Mazel.

Larson, P.J., \& Maag, J.W. (1998). Applying functional assessment in general education classrooms: Issues and recommendations. Remedial \& Special Education, 19, 338-349.

Loftus, E.F. (1979). Eyewitness testimony. Cambridge, MA: Harvard University Press.

Maag, J.W. (1991). Oppositional students or oppositional teachers?. Beyond Behavior, 2(4), 7-11.

Maag, J.W. (1992). Integrating consultation into social skills training: Implications for practice. Journal of Educational \& Psychological Consultation, 3, 233-258.

Maag, J.W. (1997a). Managing resistance: Looking beyond the child and into the mirror. In P. Zionts (Ed.), Inclusion strategies for students with learning and behavior problems (pp. 229-271). Austin, TX: Pro-Ed.

Maag, J.W. (1997b). Managing resistance: Remembering how to fly a kite. Reclaiming Children and Youth:
Journal of Emotional \& Behavioral Problems, 6(2), 114-119.

Maag, J.W. (1997c). Parenting without punishment: Making problem behavior work for you. Reclaiming Children and Youth: Journal of Emotional \& Behavioral Problems, 6(3), 176-179.

Maag, J.W. (1999). Behavior management: From theoretical implications to practical application. San Diego, CA: Singular.

Maag, J.W. (in press). Some considerations and ideas for managing resistance. Intervention in School and Clinic.

Malott, R.W., Whaley, D.L., \& Malott, M.E. (1997). Elementary principles of behavior ( $3 \mathrm{~d}$ ed.). Upper Saddle River, NJ: Prentice Hall.

McMahon, R.J., \& Forehand, R. (1988). Conduct disorders. In E.J. Mash \& LG. Terdal (Eds.), Behavioral assessment of childhood disorders (2d ed., pp. 105-153). New York: Guilford.

Miller, T. (1986). The unfair advantage. Skaneateles, NY: Lakeside.

Neel, R.S., \& Cessna, K.K. (1993). Behavioral intent: Instructional content for students with behavior disorders. In K.K. Cessna (Ed.), Instructionally differentiated programming: A needs-based approach for students with behavior disorders (pp. 31-39). Denver, CO: Colorado Department of Education.

Rhode, G., Jenson, W.R., \& Reavis, H.K. (1995). The tough kid book: Practical classroom management strategies. Longmont, CO: Sopris West.

Rhode, G., Morgan, D. P., \& Young, K. R. (1983). Generalization and maintenance of treatment gains of behaviorally handicapped students from resource rooms to regular classrooms using self-evaluation procedures. Journal of Applied Behavior Analysis, 16, 171-188.

Rocissano, L., Slade, A., \& Lynch, V. (1987). Dyadic synchrony and toddler compliance. Developmental Psychology, 23, 698-704.

Rohrbaugh, M., Tennen, H., Press, S., \& White, L. (1981). Compliance, defiance and therapeutic paradox: Guidelines for strategic use of paradoxical interventions. American Journal of Orthopsychiatry, 51, 454-467.

Rosen, S. (1982). My voice will go with you: The teaching tales of Milton H. Erickson. New York: Norton.

Rossi, E. L., Ryan, M. O., \& Sharp, F. A. (Eds.). (1983). Healing in hypnosis: The seminars, workshops, and lectures of Milton H. Erickson (Vol. 1). New York: Irvington.

Scarr, S. (1985). Constructing psychology: Making facts and fables for our times. American Psychologist, 40, 499-512.

Schoen, S. (1986). Decreasing noncompliance in a severely multihandicapped child. Psychology in the Schools, 23, 88-94. 
Schwartz, D.M., Thompson, M.G., \& Johnson, C.L. (1982). Anorexia nervosa and bulimia: The socio-cultural context. International Journal of Eating Disorders, 1, 20-36.

Shelton, J.L., \& Levy, R.L. (1981). Behavioral assignments and treatment compliance. Champaign, IL: Research Press.

Simon, D.J., \& Vetter-Zemitzsch, A. (1985). Paradoxical interventions: Strategies for the resistant adolescent. In M.K. Zabel (Ed.), TEACHING: Behaviorally disordered youth (Vol. 1, pp. 17-22). Reston, VA: Council for Children with Behavioral Disorders.

Strain, P.S., Odom, S.L., \& McConnell, S. (1984). Promoting social reciprocity of exceptional children: Identification, target behavior selection, and intervention. Remedial \& Special Education, 5(1), 21-28.
Walker, H.M., Colvin, G., \& Ramsey, E. (1995). Antisocial behavior in school: Strategies and best practices. Pacific Grove, CA: Brooks/ Cole.

Watzlawick, P. (1978). The language of change. New York: Basic Books.

Watzlawick, P., Weakland, J., \& Fisch, R. (1974). Change: Principles of problem formation and problem resolution. New York: Norton.

Zeig, J.K. (Ed.). (1985). Erickson psychotherapy: Volume I: structures. New York: Brunner/Mazel.

Zirpoli, T.J., \& Melloy, K.J. (1997). Behavior management: Applications for teachers and parents (2d ed.). Upper Saddle River, NJ: Prentice Hall. 